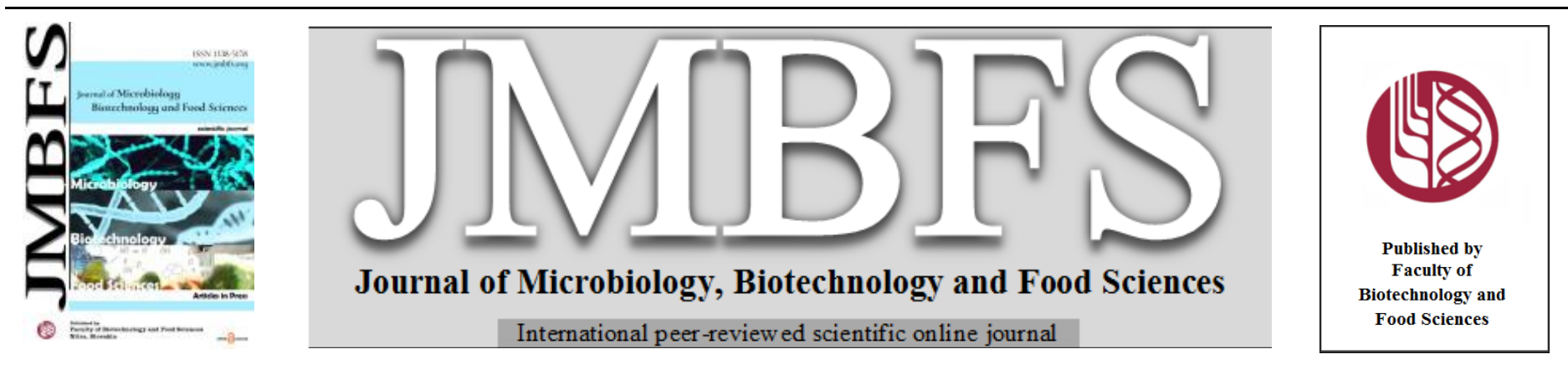

\title{
ANTIMICROBIAL, ANTIBIOFILM, AND PROBIOFILM EFFECTS OF GALLIC ACID ON EXOPOLYSACCHARIDE- DEPENDENT AND -INDEPENDENT BIOFILM OF MODEL STRAINS STREPTOCOCCUS THERMOPHILUS CNRZ 447 AND STAPHYLOCOCCUS AUREUS ATCC 43300
}

\section{Badra Boubakeur ${ }^{* 1,2}$, Moustapha Soungalo Drabo ${ }^{3}$, Hafidah Khadem ${ }^{1,4}$, Rimmibtiri Segda ${ }^{5}$, Muhammad Ajmal Shah ${ }^{6}$ and Aly Savadogo ${ }^{3}$}

Address(es): Badra Boubakeur, Ph.D.

${ }^{1}$ Faculty of Nature and Life Sciences, Ibn Khaldoun University, Tiaret 14000, Algeria.

${ }^{2}$ Laboratory for Improvement and Valorization of Local Animal Production, Ibn Khaldoun University, Tiaret 14000, Algeria.

${ }^{3}$ Laboratory of Applied Biochemistry and Immunology, University Joseph Ki-Zerbo, BP 7021 Ouagadougou 03, Burkina Faso.

${ }^{4}$ Laboratory of Bioconversion, Health Safety and Microbiological Engineering, University Mustapha Stambouli, Mascara 29000, Algeria.

${ }^{5}$ National School of Breeding and Animal Health, BP 7026 Ouagadougou 03, Burkina Faso.

${ }^{6}$ Department of Pharmacognosy, Government College University, Faisalabad 38000, Pakistan.

*Corresponding author: boubakeurbadra82@yahoo.fr/ badra.boubakeur@univ-tiaret.dz

\section{ARTICLE INFO}

Received 8. 6. 2019

Revised 31. 1. 2022

Accepted 8. 2. 2022

Published 1. 6. 2022

Regular article open 2 access

\section{ABSTRACT}

This study aimed to identify an approach that can simultaneously prevent biofilm-associated damage from Staphylococcus aureus, the most prevalent agent of mastitis in cattle in Algeria and dairy product spoiler, and improve the properties of dairy starters and probiotics Selected strains Streptococcus thermophilus CNRZ 447 and methicillin-resistant S. aureus ATCC 43300 were cultured independently in broth containing increasing concentrations of gallic acid. S. aureus ATCC 43300 was shown to be an exopolysaccharide-independen biofilm producer. Gallic acid exhibited a dose- and strain-dependent antimicrobial, antibiofilm, and probiofilm effects. The molecule of gallic acid improved the exopolysaccharide production ability of $S$. thermophilus and altered adhesion determinants (e.i., auto-aggregation and surface hydrophobicity) of both strains. This study indicated that biofilm-associated phenotypic characteristics, such as the composition of the extracellular structure, should be determinant in the action of gallic acid on microorganisms. The intriguing stimulation of $S$. aureus ATCC 43300 biofilm by gallic acid could not allow us to conclude on its use as a biofilm preventing compound. Nonetheless, gallic acid was demonstrated to be a potent antimicrobial compound against $S$. aureus and an enhancer of biofilm phenotypic characteristics (including adhesion properties and exopolysaccharide production) of $S$. thermophilus. These observations suggest that gallic acid or related phenolic compounds can be used to improve the properties of probiotics and the performance of microbial cell factories. Subsequently, gallic-acid adapted $S$. thermophilus cultures could be explored to disperse $S$. aureus in dairy products and industrial materials.

Keywords: Staphylococcus aureus, Streptococcus thermophilus, gallic acid, biofilm, exopolysaccharide, hydrophobicity, adhesion

\section{INTRODUCTION}

Biofilm is the universal and predominant lifestyle of bacteria, in which bacteria adapt their metabolism and physiology to the hostile conditions of their natura habitats and to resist external aggressions (i.e., antimicrobials and immune defenses). Biofilm is associated with the ability of bacteria to communicate through a sophisticated signal system (named quorum sensing) and to organize themselves in a highly structured sessile community (Berlanga and Guerrero, 2016; Chamignon et al., 2020). Cells composing this community can be attached to a substratum or interface and embedded in a matrix of extracellular polymeric substances that they have produced (Berlanga and Guerrero, 2016; Chamignon et al., 2020). The biofilm production ability of microorganisms has several implications. In cases of infections, industrial contaminations, and environmental pollutions, removing biofilm is difficult and thus constitutes serious ecological, economic, and public health issues (Berlanga and Guerrero, 2016). On the other hand, biofilms can be exploited for different applications. For example, biofilms are used in bioremediation treatment filters, and biofilm production ability is a desired attribute for starter's cultures or microbial cell factories (Couvigny et al. 2015; Berlanga and Guerrero, 2016, Chamignon et al., 2020)

Staphylococcus aureus ( $S$. aureus) is one of the leading causes of biofilm associated and antibiotic-resistant infections for humans and animals (Lister and Horswill, 2014; Aryee and Edgeworth, 2017). Its capacity to produce biofilm constitutes the main characteristic of its virulence and pathogenesis (Lister and Horswill, 2014; Aryee and Edgeworth, 2016). The species is ubiquitous and is skin and mucosa commensal, making of it of about $80 \%$ of nosocomial infections (Lister and Horswill, 2014). It is associated with chronic abscesses, post-surgica infections, and implants replacements. The germ also poses serious problems in the dairy and food industry, i.e., persisting contaminating of food processing environments, outbreaks of foodborne diseases, sickly livestock, drop in milk productivity, contamination of dairy products, and huge economic losses (Saidi et al., 2013; Berlanga and Guerrero, 2016). In Algeria, S. aureus is identified as the most prevalent and persisting causal pathogen of mastitis in cattle (Saidi et al. 2013). Therefore, the research of controlling strategies against $S$. aureus biofilms has become a critical concern.

Streptococcus thermophilus (S. thermophilus) has become the most prevalent used thermophilic starter in the dairy industry (i.e., in yogurt and cheese production) (Couvigny et al., 2015). The aptitude of $S$. thermophilus strains to produce biofilm has been demonstrated as a key attribute in their selection as starter cultures (Couvigny et al., 2015). However, most of the strains of $S$. thermophilus have lost over time their ability to produce biofilm (Couvigny et al., 2015). Yet recently, different strategies have been explored to enhance the biofilm production ability of beneficial bacteria. These include microbial genetic engineering, the use of natural products (i.e., phenolics), and bioprocess engineering (i.e., sonication, reactor design) (Berlanga and Guerrero, 2016; Boubakeur et al., 2018; Khadem et al., 2020). Natural products, such as phenolics, are currently intensively explored as antimicrobial, prebiotics, and biofilm controlling compounds (Borges et al., 2012; Akbas, 2015; Boubakeur et al., 2018; BourabChibane et al., 2019). The use of phenolic compounds to control biofilms stands more promising as a cost-effective strategy.

Gallic acid is one of the most predominant and abundant phenolic compounds in nature and food products. It has been widely used as an antioxidant, antimicrobial, anticancer, prebiotic, and bio-preservative agent (Khalil, 2010; Borges et al., 2012; Kahkeshani et al., 2019). It is also shown to be a potent biofilm controlling molecule (Borges et al., 2012; Akbas, 2015). The molecule of gallic acid is able to adsorb at the surface of bacteria, diffuse passively through the cytoplasm, and bind to soluble cytoplasmic proteins (Borges et al., 2013). It subsequently interferes with bacterial metabolism and quorum sensing signaling, modifies bacterial surface properties and adhesion, and thus stimulate or inhibit, strain 
dependently, the establishment of biofilms (Khalil, 2010; Borges et al., 2012; Akbas, 2015). This dual property of gallic acid (as a pro- and anti-biofilm compound) could allow designing a strategy to eliminate pathogens and enhance the biofilm production capacity of beneficial bacteria, simultaneously. Then, this study aimed to evaluate the effect of gallic acid on the biofilm production ability of a selected dairy starter $S$. thermophilus CNRZ 447 and the methicillin-resistant S. aureus ATCC 43300.

\section{MATERIAL AND METHODS}

\section{Bacterial strains}

Aliquots of bacterial strains $S$. thermophilus CNRZ 447 and S. aureus ATCC 43300 were kindly provided by the research Laboratory for Improvement and Valorization of Local Animal Production, Veterinary Sciences Institute, Ibn Khaldoun University of Tiaret (Algeria). S. thermophilus CNRZ 447 was chosen as a model dairy starter and probiotics, and $S$. aureus ATCC 43300 was selected as a methicillin-resistant $S$. aureus strain and a model pathogenic biofilm producer Sub-cultures were grown on agar M17 and agar Chapman (Pronadisa, Spain). The species were identified based on the aspects of the cultures and Gram staining. Overnight cultures were always prepared for each test.

\section{Gallic acid treatment}

Colonies of $S$. thermophilus and $S$. aureus were respectively transferred in M17 and Muller Hinton broths and incubated for $18 \mathrm{~h}$. Then, cell densities were fixed at optical densities (OD) (BIOCHROM Libra S6, UK, 565nm) $0.10(578 \mathrm{~nm})$ for $S$. thermophilus and 0.08 for $S$. aureus (providing $10^{7}-10^{8} \mathrm{CFU} / \mathrm{mL}$ ) (Andrews and Howe, 2011). The cell concentrations were further checked using agar plating. A stock solution of $15 \mathrm{mg} / \mathrm{mL}$ of gallic acid (Merck, Spain) in water and appropriate serial dilutions were prepared. Afterward, $3.5 \mathrm{ml}$ of gallic acid solution was mixed with $1.5 \mathrm{ml}$ of culture broth to achieve treatments of $0.1,0.25,0.5,1$, $1.5,5$, and $10 \mathrm{mg}$ gallic acid/ mL culture broth. Two controls were prepared using distilled water or glucose (CRAPC, Algeria) solution $(5 \mathrm{mg} / \mathrm{mL})$, respectively, instead of gallic acid, to identify the culture media effect. Microbial cell blank tubes were also realized using non-inoculated culture broth. The treatments were all run in duplicates in borosilicate glass tubes $(15 \mathrm{~mL})$ and incubated at $37^{\circ} \mathrm{C}$ for $24 \mathrm{~h}$

\section{Measurement of planktonic growth and quantification of sessile biofilm}

After incubation, $2.5 \mathrm{~mL}$ aliquot of culture broth was taken in a plastic cuvette, and the planktonic growth was measured at $578 \mathrm{~nm}$ for $S$. thermophilus and $565 \mathrm{~nm}$ for $S$. aureus (BIOCHROM Libra S6, UK). Then, the sessile biofilm production ability of both strains was assayed as described in O'Toole and Kolter (1998). Briefly, the culture broth suspension was discarded, and $10 \mathrm{~mL}$ of $1 \%$ cristal violet $(\mathrm{CV})$ was added. The tubes were incubated for 30 minutes at room temperature and thoroughly rinsed using distilled water. The cristal violet-stained and adhered cells were resuspended in $10 \mathrm{~mL}$ of $95 \%$ ethanol, and the OD was measured at $540 \mathrm{~nm}$ (BIOCHROM Libra S6, UK). Biofilm quantified as follows: Biofilm (OD) $=$ OD (CV-stained test tube) - OD (CV-stained microbial blank test tube).

Tests for adhesion determinants: Auto-aggregation and cell surface hydrophobicity

The auto-aggregation ability and the surface hydrophobicity of bacterial cells were analyzed according to Balakrishna (2013). After gallic acid treatments and incubation, cells were collected at $5000 \mathrm{~g}$ for 15 minutes (Centrifuge NF 200) then washed twice using PBS. Cell pellets were resuspended in PBS, and ODs were fixed between 0.4-0.6 (cell concentration $>10^{8} \mathrm{cfu} / \mathrm{mL}$ ) at $578 \mathrm{~nm}$ for $S$. thermophilus and $565 \mathrm{~nm}$ for S. aureus (BIOCHROM Libra S6, UK). Autoaggregation kinetics were performed as follows. Cell suspensions were vigorously mixed at a vortex and incubated at room temperature. Aliquots of 0.1 $\mathrm{mL}$ of the upper layers of the suspensions were taken at $\mathrm{t}=0,1,2,3,4$, and $5 \mathrm{~h}$, mixed with $2.4 \mathrm{~mL}$ read at the appropriate wavelength of each species. Autoaggregation percentage (A\%) was calculated : $\mathrm{A} \%(\mathrm{t})=\left(1-\mathrm{OD}_{(\mathrm{t})} / \mathrm{OD}_{(0)}\right) \times 100$ Afterward, Surface hydrophobicity was tested as follows. Two mL of cell suspension in PBS was mixed with $120 \mu \mathrm{L}$ of xylene (Merck, Spain), vigorously mixed, and left at room temperature for 30 minutes for phase separation. The optical density of the PBS phase was determined at the appropriate wavelength of each species, and the hydrophobicity percentage $(\mathrm{H} \%)$ was calculated: $\% \mathrm{H}=(1-$ $\mathrm{OD}_{\text {thereafter }} / \mathrm{OD}_{\text {before}}$ ) 100 (where, $\mathrm{OD}_{\text {before, }} \mathrm{OD}_{\text {thereafter }}$ designate optical density of the suspension before mixing xylene and after phase separation, respectively).

\section{Exopolysaccharides extraction and quantification}

After gallic acid treatments and incubation, exopolysaccharides were extracted as described in Ko et al. (2000). Briefly, two volumes of methanol and chloroform $(\mathrm{V} / \mathrm{V})$ was added and vigorously mixed. Then, the methanol layer was collected and mixed with an equal volume of ethanol. Exopolysaccharide precipitate was collected by centrifugation $\left(10000 \mathrm{~g}, 4^{\circ} \mathrm{C}, 20\right.$ minutes) (Refrigerated Centrifuge $5427 \mathrm{R}$ ), and total carbohydrate content was determined following improved Dubois' phenol-sulfuric method (Gerchakov and Hatcher, 1972).

\section{Data analysis}

All the analyses were performed in duplicate, and data were subjected to one-way ANOVA and Bonferonni post-hoc test ( 0.05 significance level). The Aggregation kinetics were fitted to the general logistic equation $\mathrm{A} \%(\mathrm{t})=\mathrm{A} /\left(\mathrm{B}+\mathrm{C} \times \mathrm{e}^{(-\mu \mathrm{t})}\right)$ according to Motulsky and Christopoulos (2003). Constants B and C were arbitrary fixed at 1 and 69000 , respectively, considering the time to set the experiment will lead to aggregation $\mathrm{A} \%(0)=0.001 \%$. The aggregation capacity and rate $\mathrm{A}$ and $\mu$, respectively, designated the asymptote of the curve and the rate of change in the exponential phase of the curve. The suitability of the models was assessed using the coefficient of determinations $\left(\mathrm{R}^{2}\right)$ and the plotting of confidence contours (via model comparison) of the equation coefficients $\mathrm{A}$ and $\mu$. All the analyses were performed using Excel 2013, and the comprehensive guide is described in Motulsky and Christopoulos (2003).

\section{RESULTS}

\section{Antimicrobial, antibiofilm and probiofilm effects of gallic acid}

Inhibition of planktonic growth and adhering cell were translated as antimicrobial and antibiofilm

Figure 1 presents the effects of gallic acid treatments on the growth and biofilm production ability of $S$. thermophilus CNRZ 447 and $S$. aureus 43300. Compared to the control and glucose, $S$. thermophilus showed a slight decrease in planktonic growth overall range of gallic acid concentrations and dose-dependent increase in biofilm production ability between 0.5 and $10 \mathrm{mg} / \mathrm{mL}$ of gallic acid treatments. In contrast, $S$. aureus revealed higher susceptibility to gallic acid treatments - which is translated by a high dose-dependent decrease in planktonic growth and an increase in biofilm biomass but low dose-dependent $(0.1-0.25 \mathrm{mg} / \mathrm{mL})$ decrease in biofilm production ability.
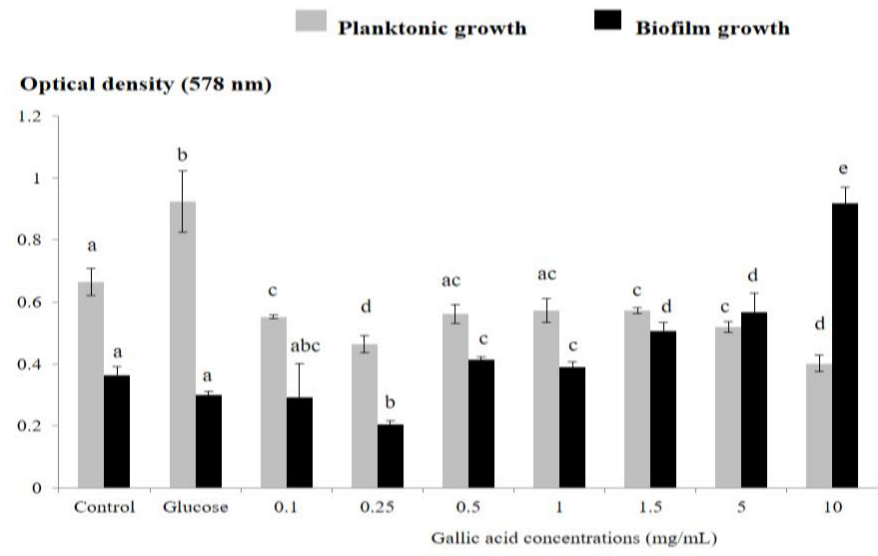

a) S. thermophilus

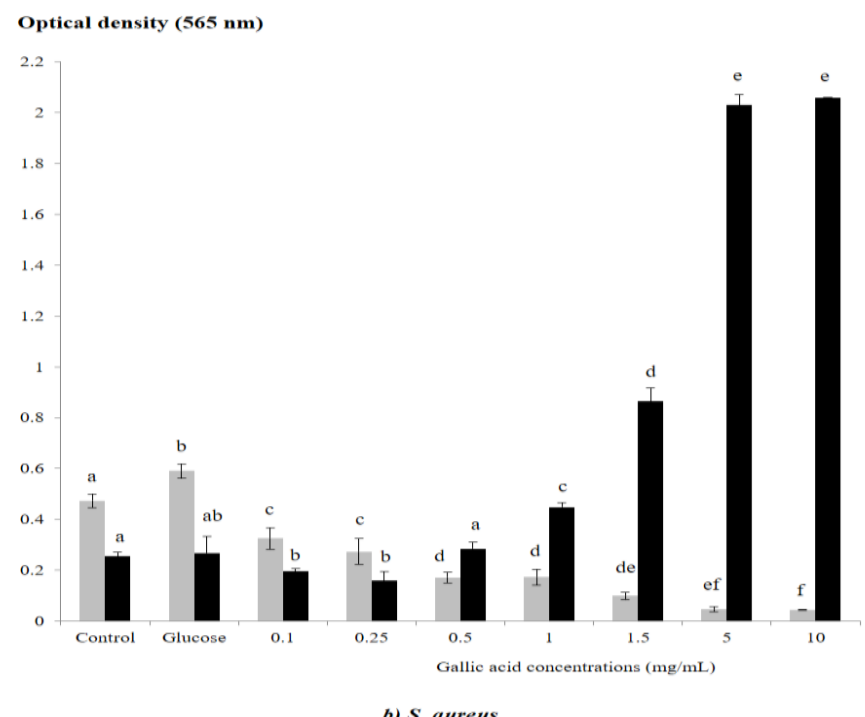

Figure 1 Antimicrobial and probiofilm effects of gallic acid on S. thermophilus CNRZ 447 and $S$. aureus ATCC 43300

Legend: The values (planktonic or biofilm growth) with different letter superscripts are significantly different $(\mathrm{p}<0.05)$ 
Effect of gallic acid treatment on the adhesion determinants Auto-aggregation capacity

Figure 2 describes the effect of selected gallic acid concentrations on the aggregation capacity of $S$. thermophilus CNRZ 447 and $S$. aureus ATCC 43300. The addition of glucose in the media, as a positive control, resulted in a decrease in $S$. thermophilus aggregation capacity but not the rate. Conversely, compared to

\section{Control Glucose}

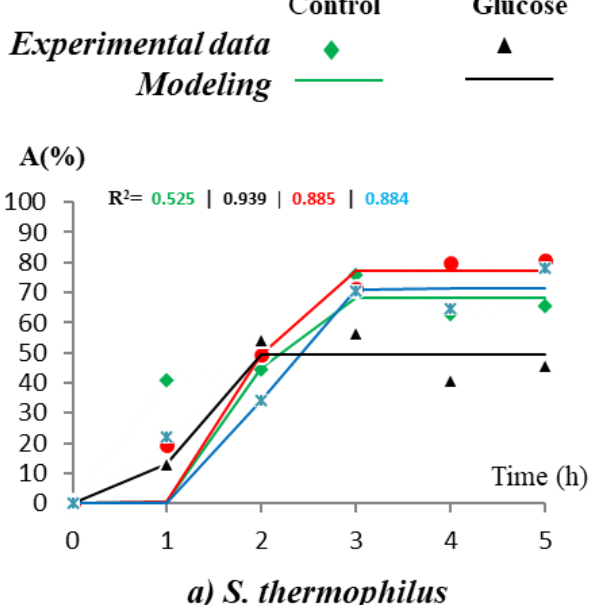

$\mu\left(\mathbf{h}^{-1}\right)$

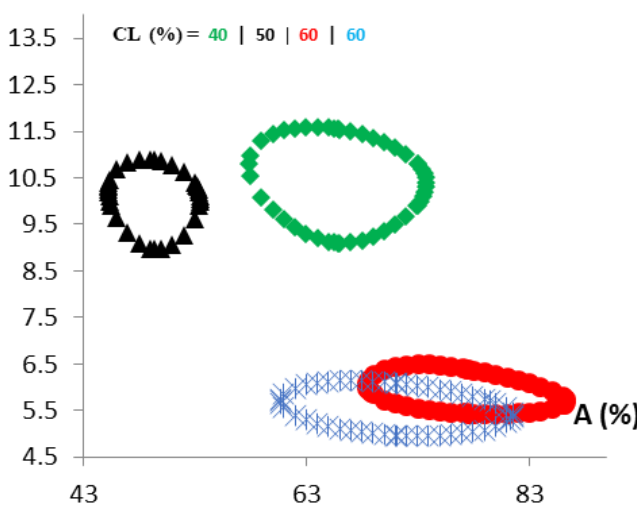

c) S. thermophilus the negative control, the treatment with gallic acid improved the aggregation rate but did not significantly improve the aggregation capacity. For $S$. aureus, compared to the negative control, both positive control (glucose) and gallic acid improved the aggregation capacity but not the aggregation rate. There was no significant difference between the aggregation capacities of $S$. thermophilus and $S$. aureus.

Gallic acid $(1 \mathrm{mg} / \mathrm{mL}) \quad$ Gallic acid $(1.5 \mathrm{mg} / \mathrm{mL})$
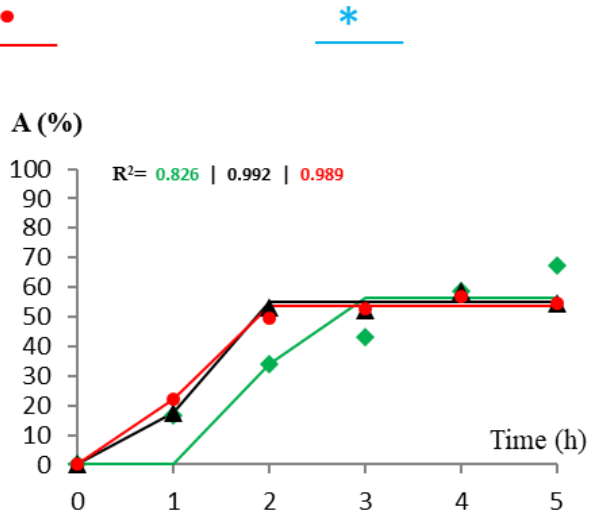

b) S. aureus

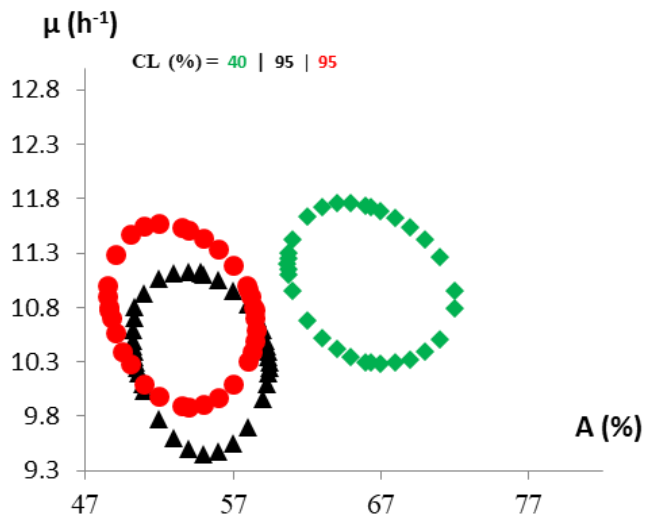

d) S. aureus

Figure 2 Effect of gallic acid treatment on aggregation capacity of $S$. thermophilus and $S$. aureus

Legend: a) and b) display the kinetics of the aggregations. c) and d) display the confidence contours of the modeled aggregation capacity A and the aggregation rate $\mu$. It was not achieved enough cell density at gallic acid concentrations higher than $1.5 \mathrm{mg} / \mathrm{mL}$ to perform the aggregation test for $S$. aureus. $\mathrm{R}^{2}$ and CL (\%) refer to the coefficient of determinations and the confidence levels of the different models, respectively. The strains are not compared due to the difference in the culture media, which could influence the aggregation properties.

\section{Surface hydrophobicity}

Figure 3 shows the effect of selected gallic acid concentrations on the surface hydrophobicity of S. thermophilus CNRZ 447 and S. aureus ATCC 43300. The treatment with gallic acid, modestly, improved the hydrophobicity of $S$. thermophilus. There was no significant difference between the different concentrations of gallic acid. In the case of $S$. aureus, both positive control (glucose) and gallic acids $(1 \mathrm{~g} / \mathrm{mL})$ significantly improved its hydrophobicity. It was not possible to collect enough concentration of $S$. aureus cells to perform the hydrophobicity test at high gallic acid concentrations $(1.5$ and $10 \mathrm{mg} / \mathrm{mL})$.

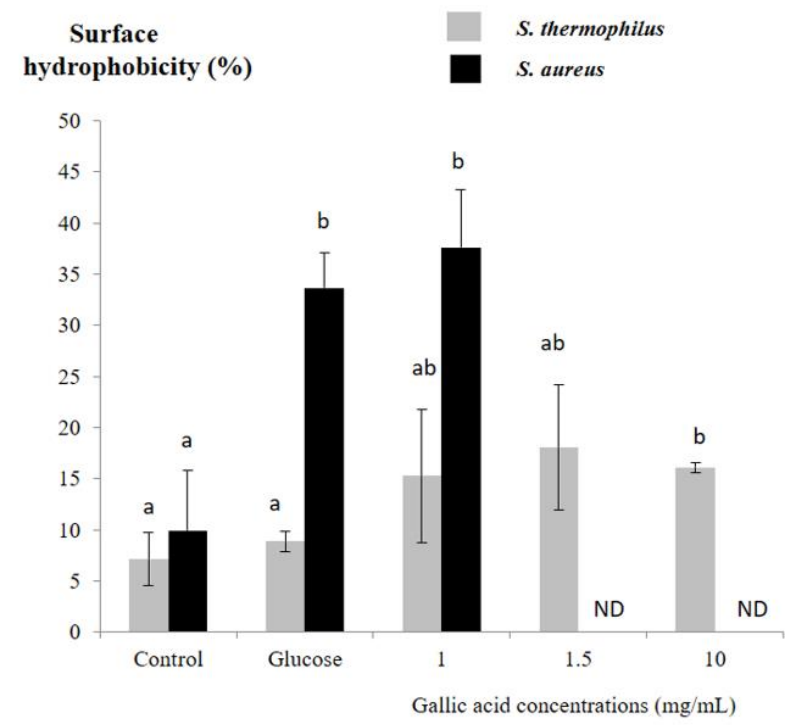

Figure 3 Effect of gallic acid treatment on surface hydrophobicity of $S$. thermophilus and S. aureus

Legend: ND refers to the fact that it was not achieved enough cell density at gallic acid 
concentrations higher than $1.5 \mathrm{mg} / \mathrm{mL}$ to perform the hydrophobicity test for $S$. aureus. The values with different letter superscripts are significantly different $(\mathrm{p}<0.05)$. The strains are not compared due to the difference in the culture media, which could influence the surface properties.

\section{Effect of gallic acid treatment on exopolysaccharide production ability}

The exopolysaccharide production ability of the strains and gallic acid effects are summarized in Table 1. Both $S$. thermophilus CNRZ 447 and $S$. aureus ATCC 43300 showed very poor exopolysaccharides production ability. S. aureus ATCC 43300 exhibited characteristic of exopolysaccharide-independent producing biofilm strain. Gallic acid significantly enhanced only the exopolysaccharide production ability of $S$. thermophilus, while glucose improved the production of exopolysaccharide by both strains.

Table 1 Effect of gallic acid on the exopolysaccharide production ability of $S$ thermophilus and S. aureus

\begin{tabular}{lcc}
\hline Treatment & \multicolumn{2}{c}{$\begin{array}{c}\text { Exopolysaccharide concentration }(\mu \text { g equivalent of } \\
\text { glucose } / \mathrm{mL})\end{array}$} \\
\hline Bacterial species & S. thermophilus & S. aureus \\
\hline Control & $12.2 \pm 1.3 \mathrm{a}$ & $\mathrm{ND}$ \\
Gallic acid $(1 \mathrm{mg} / \mathrm{mL})$ & $292.8 \pm 18.2 \mathrm{~b}$ & $\mathrm{ND}$ \\
Glucose & $131.6 \pm 16.2 \mathrm{c}$ & $128.4 \pm 6.4$ \\
p-value & 0.0097 & $\mathrm{ND}$ \\
\hline
\end{tabular}

Legend: $\mathrm{ND}=$ not determined/ below limit of detection. The values with different letter superscripts are significantly different $(\mathrm{p}<0.05)$

\section{DISCUSSION}

In agreement with the present study, Khalil (2010) reported that $S$. thermophilus tolerates low concentrations of gallic acid. He even demonstrated that gallic acid concentrations in the range of 1 to $8 \mathrm{mg} / \mathrm{mL}$ could stimulate the growth of $S$ thermophilus $\mathrm{CHCC} 3534$, and $10 \mathrm{mg} / \mathrm{mL}$ inhibits only $15 \%$ growth. Also, in line with the present study, Boubakeur et al. (2018) and Khalil (2010) showed that gallic acid could improve several properties of $S$. thermophilus, including surface properties and exopolysaccharide production, which can enhance biofilm production ability. S. thermophilus CNRZ 447 was shown to be a highly hydrophilic strain (hydrophobicity $\%<30 \%$ ), for which gallic acid only improved the hydrophobicity slightly. In contrast, Khalil (2010) reported that gallic acidconditioning could significantly modify surface properties of $S$. thermophilus CHCC 3534 from highly hydrophilic (4\%) to moderately hydrophobic (65\%).

The stimulation of biofilm production of $S$. aureus by gallic acid was conflicting with literature (Borges et al., 2013; Akbas, 2015; Oliveira et al., 2019). Gallic acid has been demonstrated as an antimicrobial and antibiofilm compound. Borges et al. (2013), in agreement, reported that a similar range of gallic acid concentrations inhibits $S$. aureus planktonic growth, but, conversely to the present study, they noted that $1 \mathrm{mg}$ of gallic acid/mL could inhibit $70 \%$ of biofilm production ability of $S$. aureus. Yet, Olievera et al. (2019) reported that it is needed very high concentration $(18 \mathrm{mg} / \mathrm{mL})$ of gallic acid to eradicate $S$. aureus biofilm. Biofilm is a protective mechanism of microorganisms and is produced in response to environmental stress or external aggression (Simoses et al., 2010). It is suggested that the applied gallic acid treatment against the studied strain of $S$ aureus might have provided sub-optimal stress that powered the biofilm production. Bacteria have different adaptation mechanisms to different levels of stress (Hill et al., 2002; Cebriàn et al., 2010). For instance, Nostro et al. (2017) showed that sub-optimal inhibitory concentration of a related phenol (carvacrol) increases the biofilm production ability of $S$. aureus.

The phenotypic characteristics associated with biofilm production are assessed to understand the responses of the studied strains of $S$. aureus to gallic acid treatment S. aureus ATCC 43300 was demonstrated to be an exopolysaccharide-independent biofilm producer. Interestingly, in agreement, Nostro et al. (2017) showed that the extracellular matrix of $S$. aureus ATCC 43300 biofilm is prevalently proteins Borges et al. (2013), based on surface tension parameters, similarly showed that gallic acid could significantly improve the hydrophobicity of a hydrophilic $S$ aureus strain. However, conversely to the present study, Cho et al. (2010), using scanning electron microscopy, showed that Camellia sinensis phenolic-rich extract could disperse $S$. aureus aggregates. The different observations indicate that possibly, proteins of $S$. aureus ATCC 43300 cell wall limited cell-to-cell adhesion (so-called aggregation) and improved the adhesion to the borosilicate glass by altering the surface hydrophobicity. Furthermore, despite the volume of biofilm biomass at higher concentrations $(>1.5 \mathrm{mg} / \mathrm{mL})$, it was not possible to harvest enough cells to analyze the aggregation and surface hydrophobicity. This suggests that gallic acid inhibited the growth of the cells and stimulated a high production of extracellular matrix for protection. Several clinical isolates of $S$. aureus have been found exopolysaccharide-independent biofilm producers, and they resist the common biofilm dissolution strategy with polysaccharide-degrading enzymes (Boles et al., 2010). To the best of our knowledge, there is no previous study that investigated the effect of gallic acid on the biofilm production ability of $S$. aureus ATCC 43300 or from the perspective of exopolysaccharide-independent biofilm producers. The molecular systems in "planktonic-to-biofilm transition" in response to "antimicrobial-induced stress" are still poorly understood and need further research (Lee et al., 2013).

In line with the literature, biofilm production ability and phenotypic characteristics, including both $S$. thermophilus and $S$. aureus species, are strain-dependent and may switch with the change in the surrounding environment or culture media (Tuncer and Tuncer, 2014; Oliveira et al., 2019; Bouarab-Chibane et al., 2019) However, there is no clear indication from the literature on how to standardize culture media to study and compared, without bias, different biofilm producer strains or multispecies biofilm. In the present study, the effect of the culture media was, however, assessed using glucose supplementation (as positive control) Glucose was selected in that it is a risk factor of biofilm-associated nosocomial infection for hyperglycaemic or diabetic patients (Waldrop et al., 2014) and pollution in the food industry (Jahid et al., 2013). In agreement with the literature, glucose improved the planktonic growth of both studied strains and the phenotypic characteristics associated with $S$. aureus biofilm, including exopolysaccharide production ability and surface hydrophobicity. Conversely, the glucose did not improve the biofilm production ability of any of the studied strains and even showed to decrease the aggregation capacity of $S$. thermophilus. Instead of borosilicate glass, both Jahid et al. (2013) and Waldrop et al. (2014) used polystyrene for the adhesion of the biofilms. The difference in the results in biofilm production could be explained by the difference in the adhesion materials (Bos et al., 1999; Busscher et al., 2008).

The present study provided further insight into the effects of gallic acid and glucose as potential biofilm controlling compounds. The observed dual effects of gallic acid (as antibiofilm and probiofilm compound) can allow designing systems to improve attributes of beneficial microorganisms and prevent biofilm-associated damages. Both glucose and gallic acid are molecules that can affect cell physiology and metabolism as substrates for microorganisms or interfering signal molecules in cell communication (such as quorum sensing in biofilm) (Khalil, 2010; Jahid et al., 2013; Borges et al., 2013; Waldrop et al., 2014). The molecules can modify the adhesion properties of bacteria, either stimulate or inhibit biofilms and enhance the synthesis of extracellular macromolecules. The influences of glucose and gallic acid on biofilm production may be practical for clinical questions and food industrials (Jahid et al., 2013; Waldrop et al., 2014). Unfortunately, the presen study could not support the use of solely gallic acid or gallic acid-rich extract as an antibiofilm agent for clinical application. Further research is needed to understand the dose-effect of gallic acid and maybe investigate the combination of gallic acid with other antimicrobial or antibiofilm compounds. Khalil (2010) and Boubakeur et al. (2018) showed that phenolic compounds or gallic acid could enhance probiotic properties of $S$. thermophilus, including an enhanced tolerance to the gastric environment, the production of bioactive compound (such antimicrobial peptides and oligosaccharides), and the antagonization of pathogenic microorganisms. This insight is interesting in that gallic acid is an abundant molecule in nature and our foods. Furthermore, one can easily imagine using gallic acid to enhance the performance of culture starters in the dairy industry and preserve products from $S$. aureus spoiling (Zhao and Shah, 2014; Amirdivani and Baba, 2015).

\section{CONCLUSION}

This study showed that antimicrobial, antibiofilm, and probiofilm effects of gallic acid on the dairy starter $S$. thermophilus CNRZ 447 and the methicillin-resistant $S$. aureus ATCC 43300 are all dose- and strain-dependent. Also, the findings provided further insight into gallic acid interaction with microorganisms. It was shown that biofilm-associated phenotypic characteristics, such as the composition of the extracellular structure, are determinant in the action of gallic acid on microorganisms. Using gallic acid as a biofilm controlling agent is to "kill two birds with one stone" approach. It was concluded that gallic acid could be used as an antimicrobial agent and probiofilm molecules to enhance the properties of probiotics and boost the performance of microbial cell factories. Further research is needed to understand the molecular systems in "planktonic-to-biofilm transition" in response to the gallic acid exposition and to explore the possibility of using gallic-acid adapted $S$. thermophilus cultures to antagonize $S$. aureus biofilm in dairy products and industrial equipment.

Acknowledgment: The research was carried out at Laboratory for Improvement and Valorization of Local Animal Production, Veterinary Sciences Institute, Ibn Khaldoun University of Tiaret. The authors express their sincere thanks and gratitude to the staff and directors of this laboratory.

Conflict of Interest: The authors declare no conflict of interest.

\section{CRediT author statement}

Badra Boubakeur: Conceptualization, Resource, Methodology, Supervision Validation, Formal analysis, Writing - Original Draft Moustapha Soungalo Drabo: Conceptualization, Methodology, Investigation, Formal analysis, Writing - Original Draft Hafidah Khadem: Conceptualization, Methodology, Resource, Writing - Reviewing and Editing Rimmibtiri Segda: Writing - Reviewing and 
Editing Muhammad Ajmal Shah: Writing - Reviewing and Editing Aly Savadogo: Writing - Reviewing and Editing.

\section{REFERENCES}

Akbas, M. Y. (2015). Bacterial biofilms and their new control strategies in food industry. In Méndez-Vilas A. (eds) The Battle Against Microbial Pathogens: Basic Science, Technological Advances and Educational Programs, Badajoz (Vol. 1). Spain: $\quad$ Formatex, 383-394pp. http://publicatio.bibl.uszeged.hu/6469/7/cover_contents.pdf

Amirdivani, S., \& Baba, A. S. H. (2014). Green tea yogurt: major phenolic compounds and microbial growth. Journal of Food Science and Technology, 52(7), 4652-4660. https://doi.org/10.1007/s13197-014-1670-6

Andrews, J. M., \& Howe, R. A. (2011). BSAC standardized disc susceptibility testing method (version 10). Journal of Antimicrobial Chemotherapy, 66(12) 2726-2757 https://doi.org/10.1093/jac/dkr359

Aryee, A., \& Edgeworth, J. D. (2016). Carriage, clinical microbiology and transmission of Staphylococcus aureus. In: Bagnoli F., Rappuoli R., Grandi G. (eds) Staphylococcus aureus. Current Topics in Microbiology and Immunology (Vol. 409). Springer, Cham. https://doi.org/10.1007/82_2016_5

Balakrishna, A. (2013). In vitro evaluation of adhesion and aggregation abilities of four potential probiotic strains isolated from guppy (Poecilia reticulata). Brazilian Archives of Biology and Technology, 56(5), 793-800. https://doi.org/10.1590/s1516-89132013000500010

Berlanga, M., \& Guerrero, R. (2016). Living together in biofilms: the microbia cell factory and its biotechnological implications. Microbial Cell Factories, 15(165). https://doi.org/10.1186/s12934-016-0569-5

Boles, B. R., Thoendel, M., Roth, A. J., \& Horswill, A. R. (2010). Identification of Genes Involved in Polysaccharide-Independent Staphylococcus aureus Biofilm $\begin{array}{llll}\text { Formation. } & \text { PLoS } & \text { ONE, } & \text { 5(4), }\end{array}$ https://doi.org/10.1371/journal.pone.0010146

Borges, A., Ferreira, C., Saavedra, M. J., \& Simões, M. (2013). Antibacterial Activity and Mode of Action of Ferulic and Gallic Acids Against Pathogenic Bacteria. Microbial Drug Resistance, 19(4), 256-265 https://doi.org/10.1089/mdr.2012.0244

Borges, A., Saavedra, M. J., \& Simões, M. (2012). The activity of ferulic and gallic acids in biofilm prevention and control of pathogenic bacteria. Biofouling, 28(7), 755-767. https://doi.org/10.1080/08927014.2012.706751

Bos, R., van der Mei, H. C., \& Busscher, H. J. (1999). Physico-chemistry of initial microbial adhesive interactions - its mechanisms and methods for study. FEMS Microbiology Reviews, 23(2), 179-229. https://doi.org/10.1111/j.1574 6976.1999.tb00396.x

Bouarab-Chibane, L., Forquet, V., Lantéri, P., Clément, Y., Léonard-Akkari, L., Oulahal, N., ... Bordes, C. (2019). Antibacterial Properties of Polyphenols: Characterization and QSAR (Quantitative Structure-Activity Relationship) Models. Frontiers in Microbiology, 10. https://doi.org/10.3389/fmicb.2019.00829 Boubakeur, B., Drabo, M. S., Khadem, H., Mullier, C., \& Tirtouil, A. (2018) Influence of the exopolysaccharides of polyphenol-conditioned lactic acid bacteria on gut microecology and bacterial translocation. Ukrainian Journal of Ecology, 8(3), 1-9. https://www.ujecology.com/articles/influence-of-theexopolysaccharides-of-polyphenolconditioned-lactic-acid-bacteria-on-gutmicroecology-and-bacterial-tran.pdf

Busscher, H. J., Norde, W., \& Van Der Mei, H. C. (2008). Specific molecular recognition and nonspecific contributions to bacterial interaction forces. Applied $\begin{array}{lll}\text { and environmental microbiology, 74(9), 2559-2564 } & \end{array}$ https://doi.org/10.1128/aem.02839-07

Cebrián, G., Sagarzazu, N., Pagán, R., Condón, S., \& Mañas, P. (2010) Development of stress resistance in Staphylococcus aureus after exposure to sublethal environmental conditions. International Journal of Food Microbiology, 140(1), 26-33. https://doi.org/10.1016/j.ijfoodmicro.2010.02.017

Chamignon, C., Guéneau, V., Medina, S., Deschamps, J., Gil-Izquierdo, A. Briandet, R., ... Bermúdez-Humarán, L. G. (2020). Evaluation of the Probiotic Properties and the Capacity to Form Biofilms of Various Lactobacillus Strains. Microorganisms, 8(7), 1053. https://doi.org/10.3390/microorganisms8071053 Cho, Y.-S., Oh, J. J., \& Oh, K.-H. (2010). Antimicrobial activity and biofilm formation inhibition of green tea polyphenols on human teeth. Biotechnology and Bioprocess Engineering, 15(2), 359-364. https://doi.org/10.1007/s12257-0090195-8

Couvigny, B., Thérial, C., Gautier, C., Renault, P., Briandet, R., \& Guédon, E. (2015). Streptococcus thermophilus Biofilm Formation: A Remnant Trait of Ancestral Commensal Life? PLOS ONE, 10(6), e0128099. https://doi.org/10.1371/journal.pone.0128099

Gerchakov, S. M., \& Hatcher, P. G. (1972). improved technique for analysis of carbohydrates in sediments1. Limnology and Oceanography, 17(6), 938-943. https://doi.org/10.4319/1o.1972.17.6.0938

Hill, C., Cotter, P. D., Sleator, R. D., \& Gahan, C. G. (2002). Bacterial stress response in Listeria monocytogenes: jumping the hurdles imposed by minimal processing. International Dairy Journal, 12(2-3), 273-283. https://doi.org/10.1016/s0958-6946(01)00125-X

Jahid, I. K., Lee, N.-Y., Kim, A., \& Ha, S.-D. (2013). Influence of Glucose Concentrations on Biofilm Formation, Motility, Exoprotease Production, and
Quorum Sensing in Aeromonas hydrophila. Journal of Food Protection, 76(2), 239-247. https://doi.org/10.4315/0362-028x.jfp-12-321

Khadem, H., Tirtouil, A. M., Drabo, S. M., \& Boubakeur, B. (2020). Ultrasound conditioning of Streptococcus thermophilus CNRZ 447: growth, biofilm formation , exopolysaccharide production , and cell membrane permeability. BioTechnologia, 101(2), 159-165. http://doi.org/10.5114/bta.2020.94774

Khalil, R. K. S. (2010). Influence of gallic acid and catechin polyphenols on probiotic properties of Streptococcus thermophilus CHCC 3534 strain. World Journal of Microbiology and Biotechnology, 26(11), 2069-2079. https://doi.org/10.1007/s11274-010-0393-8

Kahkeshani N, Farzaei F, Fotouhi M, Alavi SSH, Bahramsoltani R, Naseri R, Momtaz S, Abbasabadi Z, Rahimi R, Farzaei MH, Bishayee A. Pharmacological effects of gallic acid in health and diseases: A mechanistic review. Iran J Basic Med Sci 2019; 22:225-23 https://doi.org/10.22038/ijbms.2019.32806.7897

Ko, S.-H., Lee, H. S., Park, S. H., \& Lee, H. K. (2000). Optimal conditions for the production of exopolysaccharide by marine microorganism Hahella chejuensis Biotechnology and Bioprocess Engineering, 5(3), 181-185 https://doi.org/10.1007/bf02936591

Lee, H.-Y., Zou, Y., \& Ahn, J. (2013). Physiochemical and molecular properties of antimicrobial-exposed Staphylococcus aureus during the planktonic-to-biofilm transition. Annals of Microbiology, 63(3), 1213-1217. https://doi.org/10.1007/s13213-012-0572-y

Lister, J. L., \& Horswill, A. R. (2014). Staphylococcus aureus biofilms: recent developments in biofilm dispersal. Frontiers in Cellular and Infection Microbiology, 4. https://doi.org/10.3389/fcimb.2014.00178

Motulsky, H., \& Christopoulos, A. (2003). Fitting models to biological data using linear and nonlinear regression: A practical guide curve fitting. Graph Pad Prism (version 4), 80-127. https://www.facm.ucl.ac.be/cooperation/Vietnam/WBIVietnam-October-2011/Modelling/RegressionBook.pdf

Nostro, A., Marino, A., Ginestra, G., Cellini, L., Di Giulio, M., \& Bisignano, G. (2017). Effects of adaptation to carvacrol on Staphylococcus aureus in the planktonic and biofilm phases. Biofouling, 33(6), 470-480. https://doi.org/10.1080/08927014.2017.1323080

Oliveira, A. P. D. de, Costa, M. M. da, Nogueira, D. M., \& Dias, F. S. (2019) Characterisation of Staphylococcus aureus strains from milk and goat cheese and evaluation of their inhibition by gallic acid, nisin and velame of the Brazilian caatinga. International Journal of Dairy Technology, 73(2), 345-356. https://doi.org/10.1111/1471-0307.12673

O'Toole, G. A., \& Kolter, R. (1998). Initiation of biofilm formation in Pseudomonas fluorescens WCS365 proceeds via multiple, convergent signalling pathways: a genetic analysis. Molecular Microbiology, 28(3), 449-461. https://doi.org/10.1046/j.1365-2958.1998.00797.x

Saidi, R., Khelef, D., \& Kaidi, R. (2013). Subclinical mastitis in cattle in Algeria: Frequency of occurrence and bacteriological isolates. Journal of the South African Veterinary Association, 84(1). https://doi.org/10.4102/jsava.v84i1.929

Simões, M., Simões, L. C., \& Vieira, M. J. (2010). A review of current and emergent biofilm control strategies. LWT - Food Science and Technology, 43(4), 573-583. https://doi.org/10.1016/j.lwt.2009.12.008

Tuncer, B. O., \& Tuncer, Y. (2014). Exopolysaccharide producer Streptococcus thermophilus ST8.01 strain; a potential probiotic culture. GIDA, 39(4), 195-202 https://app.trdizin.gov.tr/makale/TVRneE9URTRPQT09/exopolysaccharideproducer-streptococcus-thermophilus-st8-01-strain-a-potential-probiotic-culture. Waldrop, R., McLaren, A., Calara, F., McLemore, R. (2014). Biofilm growth has a threshold response to glucose in Vitro. Clinical Orthopaedic and Related Research, 472, 3305-3310. https://doi.org/10.1007/s11999-014-3538-5

Zhao, D., \& Shah, N. P. (2014). Effect of tea extract on lactic acid bacterial growth, their cell surface characteristics and isoflavone bioconversion during soymilk fermentation. Food Research International, 62, 877-885 https://doi.org/10.1016/j.foodres.2014.05.004 